OPEN ACCESS

Edited by:

Russell Kabir,

Anglia Ruskin University,

United Kingdom

Reviewed by:

Divya Vinnakota,

Anglia Ruskin University,

United Kingdom

Nazeeba Siddika

University of Oulu, Finland

Sujita Kumar Kar,

King George's Medical

University, India

*Correspondence: Masoud Mohammadnezhad

masoud.m@fnu.ac.fj

Specialty section: This article was submitted to

Public Mental Health,

a section of the journal

Frontiers in Public Health

Received: 23 February 2021 Accepted: 30 March 2021

Published: 10 May 2021

Citation:

Odrovakavula L,

Mohammadnezhad $M$ and Khan S (2021) A Survey on Wellness and lts Predictors Amongst Fiji High School

Front. Public Health 9:671197. doi: 10.3389/fpubh.2021.671197

\section{A Survey on Wellness and Its Predictors Amongst Fiji High School Students}

\author{
Latileta Odrovakavula, Masoud Mohammadnezhad* and Sabiha Khan \\ School of Public Health and Primary Care, Fiji National University, Suva, Fiji
}

Background: Adolescent population face a number of health concerns which calls for objective and comprehensive assessment of their wellness during their critical development phase. This study aimed to determine adolescent wellness and its predictors amongst adolescents in secondary schools in Fiji.

Methods: This quantitative cross sectional study was conducted in four purposively selected schools in Suva and the greater Suva area, Fiji, between August and September, 2019. Students of Fijian nationality, enrolled into years 11-13 in the selected schools were purposively selected. A structured self-administered questionnaire was used to collect data on four dimensions of wellness including physical, emotional, social, and spiritual. Spearman's Rho correlation was conducted to test for associations. Descriptive and inferential statistical tests were applied to analyze the data by the SPSS software version 25. A $p$-value $<0.05$ was considered significant.

Results: A total of 350 students participated in the study. Mean raw scores for wellness dimensions were as follows: physical $=51$ (out of 60 ), psychological $=63$ (out of 80 ), social $=42$ (out of 50 ), and spiritual $=34$ (out of 40 ). For overall wellness, two significant differences were observed: students of Fijian Itaukei descent (193.68 \pm 14.2) and participants with a family income of $\$ 40,000-50,000(199.08 \pm 12.60)$ ( $p$ $=0.04$ ) had a higher overall wellness score. There were three significant differences observed for psychological wellness dimension; Fijians of Indian descent (64.68 \pm 9.30), participants enrolled into year $13(64.68 \pm 9.30)$ and those with a family income of $\$ 40,000-50,000$ had higher psychological score. For social wellness, a significant difference was observed: Itaukei participants had higher scores (43.34 \pm 4.42$)$ when compared to other ethnic groups $(p<0.05)$. In terms of spiritual wellness, a significant difference was observed for ethnicity: Itaukei participants had a higher mean score (35.59 \pm 4.26 ) when compared to other ethnic groups $(p<0.05)$. Strong correlations were observed for all dimensions of wellness.

Conclusions: Findings of this study highlighted different factors affecting adolescents' wellness in Fiji. It is recommended that health education and awareness program be carried out for developing adolescent wellness by considering these factors. It is also recommended that parental and family support are provided to adolescents.

Keywords: wellness, high school students, perceptions, predictors, Fiji 


\section{BACKGROUND}

According to World Health Organization (WHO) (2018), adolescents make up around 1.2 billion of the world's population (1). The adolescent years' poses as a critical phase of an individual's life and this is attributed to several factors. These include, the occurrence of rapid development and the need to apply decision making which influences habits that potentially influence adult onset of diseases and health issues (2). A range of health concerns are highlighted for adolescents. These range from premature death, illness, and injuries. In 2016 alone, more than 1.1 million adolescents died from preventable diseases or causes. Such statistics highlights the need to focus on of risky behaviors such as consumption of alcohol, tobacco use, physical inactivity, and unsafe sexual practices. These risky behaviors hinder adolescent growth and development and prevents them from reaching their full potential and optimal health (1). Health experts agree to the need of objectively and comprehensively assessing adolescent wellbeing at their critical development phase with the aim of progress toward healthy habits, influencing and supporting wellness (3).

Wellness is defined as, viewing individuals and their health from a holistic perspective that includes several dimensions involving the mind, body, spirit, and community interactions or social bonds (4). Previous literature supports wellness as a multi-dimensional concept consisting of interrelated components (5). For Fiji, the Wellness Fiji policy, considers seven dimensions, which includes social, spiritual, environmental, occupational, psychological, physical, and financial wellness (6). Literature also supports that for wellness to occur, there needs to be a balance between these dimensions (7).

Predictors and influences of adolescent wellness have been globally established. Review of literature indicates that for physical wellness, the predictors include physical activity, nutrition, and substance use $(5,8-12)$. Predictors for psychological wellness include self-concept and self-esteem (13-16). Family peers and school support have been observed to influence adolescent social wellness $(13,17-19)$. In terms of spiritual wellness, events such as experience of new social pressures, physical health/biological changes are observed to influence spiritual wellness (20).

The Fiji Ministry of Health and Medical Services (MoHMS) have seen the strengthening of the child health services and programs in the last 10 years with little investments in the health and well-being of adolescents (21). The adolescent and youth population in Fiji (10-24-Year-olds) comprises more than $25 \%$ of the total population (22). This is the population that will become adult citizens of the country and investing in them now, assures this group of young people have a chance to live to their fullest potential and obtain optimal health (6).

There is currently no data or research which specifically focuses on adolescent wellness in Fiji. To effectively implement interventions and action plans, data on adolescent wellness needs to be established. Therefore, the purpose of this paper is to determine adolescent wellness and its predictors amongst adolescents in secondary schools in Fiji.

\section{MATERIALS AND METHODS}

\section{Study Design and Setting}

A cross-sectional study using a two stage cluster sampling was performed between August and September, 2019 in Suva, Fiji.

The first cluster considered the geographical location of the schools and these were divided to the four areas of Suva, Lami, Nasinu, and Nausori. The second cluster, considered the urban or peri-urban locations of the schools. A list from the Ministry of Education, Heritage and Arts (MoEHA) detailed the locations of the schools. From this school list, study sites were purposively selected to ensure there were representatives of both peri-urban and urban schools. It was also ensured that there was representation of ethnic, religious, and gender groups.

The study included 350 secondary school students enrolled in four purposively selected high schools in Suva and the greater Suva area, Fiji.

The following inclusion criteria were used; students of Fijian nationality enrolled into school grade or years 11-13 in the selected schools. An information sheet was provided to the participants, this briefly explained the study purpose. These consent forms were printed in three languages; English, Itaukei, and Hindi. Those with parental consent were allowed to participate in the study. These students were also provided assent forms to indicate their willingness to participate in the study. Students above the age of 18 were only provided assent forms.

\section{Data Collection Tool}

A structured self-administered questionnaire was used to explore the perceptions of students toward adolescent wellness. Based on the four dimensions of physical wellness, psychological wellness, social, and spiritual wellness, questions were sourced from similar studies conducted on adolescent wellness $(23,24)$. Two questionnaires used by Spurr (2009) and Goodwin (2009) highlighted questions that were aligned to the objectives of this study and these questions were modified to the context of this study's setting $(23,24)$. Questionnaire by Spurr had 5 sections and 64 items whilst questionnaire by Goodwin (2009) had one overall section and 36 questions. Spurr (2009) had used the validated Adolescent Wellness Survey (AWS) created by Sharkey (1999) who assessed adolescent wellness amongst high school students in the United States. Goodwin (2009) had used the validated Perceived Wellness Survey (PWS). The original PWS had a total of 69-item questionnaire with six scales (25). Wellness related perceptions statements from these questionnaires were selected to develop the tool for this research quantitative tool. These questions were based on physical wellness, psychological wellness, social wellness, and spiritual wellness.

For this study, the questionnaire had six sections; section 1: demographic information (5 questions), section 2: perception of general wellness (5 questions), section 3: adolescent physical wellness (12 questions), section 4: adolescent spiritual wellness (8 questions), section 5: adolescent psychological wellness (16 questions), and section 6: adolescent social wellness (10 questions). A five-point Likert scale was used to measure adolescents' level of wellness. For the Likert scoring, strongly agree was given five points, agree had a score of 4 , neutral 
scored at 3, disagree scored 2, and strongly disagree scored 1 . For negatively worded statements, the codes were reversed with strongly disagree scoring the highest at 5 scores, to strongly agree scoring, 1. Each dimension of wellness had a minimum and maximum score. Physical wellness dimension had a maximum score of 60 and a minimum score of 12 . Spiritual wellness had a maximum score of 40 and a minimum score of 8 . Psychological wellness had a maximum of 80 and a minimum score of 16 and social wellness had a maximum score of 50 and a minimum score of 10. All questionnaires were printed in the English language as study participants were students of high schools where English is commonly used, developing the questionnaire in other languages was not required.

To ensure the study used good measurement tools, the validity and reliability of the data collection tool were checked. Validity considers the ability of tool to measure what it is supposed to measure and does so properly without including other factors (26). To test content validity, advice and reviews from academic staff that are considered experts in the field of wellness and health promotion was obtained. These academic reviews ensured questionnaire content was relevant and in alignment with the study's aim and objectives. The questionnaire was modified based on comments received.

Reliability test was also conducted for the survey questionnaire Likert scale items. Reliability is the degree in which a measurement tool or procedure is able to produce consistent results (26). Reliability of the item scale was calculated via Cronbach's alpha, indicating an acceptable internal consistency $(\alpha=0.92)$.

\section{Study Procedure}

Upon ethical approval, endorsement was sorted from MoEHA Research and Development section. A list of secondary school located in Suva was obtained from MoEHA. This enabled the selection of the schools to participate in the study.

Once schools were selected, arrangements were made for school visits; this allowed the researcher to conduct a courtesy visit to school management, seeking student and teachers' participation. Upon the receipt of approval, a focal person was identified for communication purposes. A meeting with the school's appointed focal staff was then conducted for further arrangements and briefing about the study importance, its aims and objectives. Through the focal staff, the rest of the academic staff were briefed about the study details and their role in the study participants' recruitment. The school focal person was requested to provide data collection dates for the school.

Students who met the inclusion criteria were invited to fill in the self-administered structured questionnaire. Time utilized to fill questionnaires was $\sim 20-30 \mathrm{~min}$. Clarifications on the questionnaire was provided when needed. Students were advised to submit their filled questionnaires after completion.

\section{Statistical Analysis}

Data was exported and used in Microsoft Excel for data cleaning; cleaned data was imported back into Statistical Package for the Social Science (SPSS), version 25 for analysis. Due to the nonparametric nature of the data, Spearman's Rho correlation was
TABLE 1 | Socio-demographic characteristics of participants.

\begin{tabular}{|c|c|}
\hline Characteristics & n (\%) \\
\hline Age (Mean \pm SD) & $17.5 \pm 0.9$ \\
\hline \multicolumn{2}{|l|}{ Gender } \\
\hline Male & $137(39.1)$ \\
\hline Female & $213(60.9)$ \\
\hline \multicolumn{2}{|l|}{ Age } \\
\hline 16 years old & $87(24.9)$ \\
\hline 17-18 years old & 239 (68.3) \\
\hline 19-20 years old & $24(6.9)$ \\
\hline \multicolumn{2}{|l|}{ Ethnicity } \\
\hline Itaukei & $205(58.6)$ \\
\hline Indo-Fijian & $118(33.7)$ \\
\hline Others & $27(7.7)$ \\
\hline \multicolumn{2}{|l|}{ Education Level } \\
\hline Years 11 & $111(31.7)$ \\
\hline Years 12 & $161(46.0)$ \\
\hline Years 13 & $78(22.3)$ \\
\hline \multicolumn{2}{|c|}{ Annual Family Income (FJD) } \\
\hline Below $\$ 5,000$ & $82(23.4)$ \\
\hline$\$ 5,000-10,000$ & 57 (16.3) \\
\hline$\$ 10,000-20,000$ & $77(22.0)$ \\
\hline$\$ 30,000-40,000$ & $54(15.4)$ \\
\hline$\$ 40,000-50,000$ & $25(7.1)$ \\
\hline Above $\$ 50,000$ & $24(6.9)$ \\
\hline
\end{tabular}

conducted to test for associations. To examine the differences of means amongst the independent variables, Anova and KruskalWallis $\mathrm{H}$-test were used. Analysis of Variance (ANOVA) was conducted for parametric data and Kruskal-Wallis $H$-test was conducted for non-parametric data. A $p$-value $<0.05$ was considered significant.

\section{Ethical Considerations}

The study was approved by College of Medicine, Nursing and Health Sciences' (CMNHS) Health Research Ethics Committee (CHREC) at Fiji national University (FNU). Facility approval was endorsed by the Research and Development section of the Ministry of Education, Heritage and Arts (MoEHA). Consent forms to obtain a parent or guardian approval were provided to students, below the age 18 years.

\section{RESULTS}

\section{Demographic Characteristics of Participants}

A total of 400 questionnaires were distributed, the study had a response rate of $87.5 \%$ with 350 questionnaire completed. Table 1 below, summarizes the socio demographic characteristics of participants. Participants' age, ranged from 16 to 20 years with the mean age of $17.5(\mathrm{SD}=+0.9)$. For this study's participants, more female students $(60.9 \%)$ were part of the survey compared to male students $(39.1 \%)$. In terms of ethnicity, there were more 
TABLE 2 | Level of wellness.

\begin{tabular}{|c|c|c|c|}
\hline & Points scale & N (\%) & Mean $( \pm S D)$ \\
\hline $\begin{array}{l}\text { Overall } \\
\text { Wellness }\end{array}$ & & & $188 \pm 18$ \\
\hline Low & $56-179$ & 90 (25.7) & \\
\hline High & $180-190$ & $91(26.0)$ & \\
\hline Very High & $191-219$ & 169(48.3) & \\
\hline $\begin{array}{l}\text { Physical } \\
\text { wellness }\end{array}$ & & & $51 \pm 5$ \\
\hline Low & $14-49$ & 98 (28.0\%) & \\
\hline High & $50-52$ & 83 (23.7\%) & \\
\hline Very High & $53-60$ & 169 (48.3\%) & \\
\hline $\begin{array}{l}\text { Psychological } \\
\text { wellness }\end{array}$ & & & $63 \pm 7$ \\
\hline Low & $21-59$ & $91(26.0)$ & \\
\hline High & $60-63$ & 85 (24.3) & \\
\hline Very High & 64-78 & $174(49.7)$ & \\
\hline Social wellness & & & $42 \pm 5$ \\
\hline Low & $10-40$ & 101 (28.9) & \\
\hline High & $41-44$ & 108(30.9) & \\
\hline Very High & $45-50$ & 141 (40.3) & \\
\hline $\begin{array}{l}\text { Spiritual } \\
\text { wellness }\end{array}$ & & & $34 \pm 4$ \\
\hline Low & $8-32$ & $101(28.9)$ & \\
\hline High & $33-35$ & 79 (22.6) & \\
\hline Very High & $36-40$ & 170 (48.6) & \\
\hline
\end{tabular}

Fijians of Itaukei descent (58.6\%) compared to other races. Most of the participants were enrolled into the Year 12 level (46\%). Income levels provided by the students indicated that most of the students' family earned below $\$ 5,000$ (23.4\%) and between $\$ 10,000-20,000$ (22\%) annually.

\section{Level of Wellness}

The mean adjusted overall wellness score was 188 with the range of 56-219. Mean raw scores for wellness dimensions were as follows: physical $=51$ (out of 60 ), psychological $=63$ (out of 80 ), social $=42$ (out of 50 ), and spiritual $=34$ (out of 40 ). In terms of overall wellness, nearly half of the participants $(48.3 \%)$ had very high wellness scores. About $26 \%$ of participants scored high-level scores while another $25.7 \%$ had low scores. In terms of physical wellness, the majority of the participants scored very high scores $48.3 \%$ while $23.7 \%$ scored high scores and around $28.0 \%$ had low scores.

Similar results were found for psychological wellness; nearly half of the participants (49.7\%) had very high wellness scores. About $26 \%$ of participants scored high level of scores while another $23.4 \%$ had low scores. For social wellness, $40.3 \%$ scored very high scores, with $30.9 \%$ scoring high scores and $28.9 \%$ scored low scores. In terms of spiritual wellness, $48.6 \%$ scored very high scores, $22.6 \%$ scored high scores, and $28.9 \%$ scored low scores. Table 2 presents participants level of wellness.

\section{Predictors of Wellness}

ANOVA analysis of overall wellness and each dimension of wellness scores, based on the study's independent variables are presented in Table 3.

\section{Overall Wellness}

Significant differences were observed for ethnicity $(p=0.02)$ where Fijians of Itaukei descent students had higher overall wellness scores $(193.68 \pm 14.2)$ as compared to those from other ethnic backgrounds. Participants with a family income of $\$ 40,000-50,000$ had a higher overall wellness score (199.08 \pm $12.60)$ when compared with those in other income categories and this was observed to be statistically significant $(p=0.04)$.

\section{Physical Wellness}

There were no significant differences observed between the independent variables and physical wellness.

\section{Psychological Wellness}

There were three significant differences observed for the psychological wellness dimension. This was observed for ethnicity, where Fijians of Indian descent had higher scores $(64.68 \pm 9.30)$ when compared to other ethnic groups; Itaukei $(63.00 \pm 5.53)$, and others $(59.40 \pm 6.38),(p<0.01)$. Significant difference $(p=0.04)$ was observed for education level, participants enrolled in Year 13 had higher scores (65.07 $\pm 5.06)$ when compared with those enrolled in Year 12 (62.64 $\pm 7.80)$ and Year $11(62.97 \pm 7.40)$. In terms of family income, participants with a family income of $\$ 40,000-50,000$ had a higher score $(65.08 \pm 6.04)$ when compared with those in other income categories $(p=0.01)$.

\section{Social Wellness}

For social wellness, a significant difference was observed in terms of ethnicity, as Fijians of Itaukei descent participants, had higher scores $(43.34 \pm 4.42)$ when compared to other ethnic groups $(p<0.05)$.

\section{Spiritual Wellness}

In terms of spiritual wellness, a significant difference was observed for ethnicity, as Fijians of Itaukei descent students had a higher mean score $(35.59 \pm 4.26)$ when compared to other ethnic groups $(p<0.05)$.

\section{Correlations Between Wellness Dimension Scores and Overall Wellness}

Correlations between wellness dimensions and the overall wellness composite score are presented in Table 4. Strong or very strong correlations were observed for all dimensions: physical wellness score $(r=0.66, p<0.01)$, psychological wellness score $(r=0.80, p<0.01)$, social wellness score $(r=0.71, p<0.01)$, and spiritual wellness score $(r=0.80, p<0.01)$. These results show that there are strong positive relationships between the perceptions of each wellness dimensions and overall wellness.

Correlation analysis between physical wellness items and overall wellness produced positive, low, weak, and moderate levels of associations. These included perceptions related to weight, diet, and physical activity. A positive moderate 
TABLE 3 | ANOVA of demographic variables, wellness composite, and wellness dimensions.

\begin{tabular}{|c|c|c|c|c|c|c|c|c|c|c|}
\hline & \multicolumn{2}{|c|}{ Overall wellness } & \multicolumn{2}{|c|}{ Physical wellness } & \multicolumn{2}{|c|}{ Psychological wellness } & \multicolumn{2}{|c|}{ Social wellness } & \multicolumn{2}{|c|}{ Spiritual wellness } \\
\hline & mean $\pm \mathrm{Sd}$ & $p$-value & mean \pm Sd & $p$-value & mean $\pm \mathrm{Sd}$ & $p$-value & mean \pm Sd & $p$-value & mean \pm Sd & $p$-value \\
\hline Gender & & 0.952 & & 0.374 & & 0.068 & & 0.775 & & 0.081 \\
\hline Male & $192.28 \pm 17.89$ & & $50.94 \pm 6.14$ & & $64.16 \pm 6.98$ & & $42.76 \pm 5.07$ & & $34.40 \pm 4.20$ & \\
\hline Female & $192.15 \pm 19.05$ & & $51.69 \pm 5.29$ & & $62.17 \pm 7.29$ & & $42.93 \pm 5.52$ & & $34.79 \pm 5.19$ & \\
\hline Age & & 0.565 & & 0.289 & & 0.606 & & 0.525 & & 0.739 \\
\hline 16 years old & $192.45 \pm 18.91$ & & $51.28 \pm 6.08$ & & $63.42 \pm 8.26$ & & $43.22 \pm 5.08$ & & $34.51 \pm 4.78$ & \\
\hline $17-18$ years old & $191.74 \pm 18.73$ & & $51.29 \pm 5.51$ & & $63.10 \pm 6.91$ & & $42.70 \pm 5.40$ & & $34.63 \pm 4.88$ & \\
\hline $19-20$ years old & $195.96 \pm 15.91$ & & $52.96 \pm 5.17$ & & $64.62 \pm 5.85$ & & $43.16 \pm 5.80$ & & $35.20 \pm 4.58$ & \\
\hline Ethnicity & & $0.025^{\star}$ & & 0.652 & & $<0.0001^{*}$ & & $0.004^{\star}$ & & $0.0001^{*}$ \\
\hline Itaukei & $193.68 \pm 14.20$ & & $51.75 \pm 4.48$ & & $63.00 \pm 5.53$ & & $43.34 \pm 4.42$ & & $35.59 \pm 4.26$ & \\
\hline Fijians of Indian Descent & $191.63 \pm 23.86$ & & $51.02 \pm 7.13$ & & $64.68 \pm 9.30$ & & $42.75 \pm 6.19$ & & $33.16 \pm 5.34$ & \\
\hline Others & $183.48 \pm 19.77$ & & $50.44 \pm 6.21$ & & $59.40 \pm 6.38$ & & $39.74 \pm 6.67$ & & $33.88 \pm 4.91$ & \\
\hline Education Level & & 0.340 & & 0.433 & & $0.042^{*}$ & & 0.509 & & 0.165 \\
\hline Years 11 & $190.95 \pm 17.51$ & & $50.91 \pm 5.53$ & & $62.97 \pm 7.40$ & & $42.50 \pm 5.01$ & & $34.56 \pm 4.33$ & \\
\hline Years 12 & $191.78 \pm 21.21$ & & $51.48 \pm 6.07$ & & $62.64 \pm 7.80$ & & $42.85 \pm 5.74$ & & $34.80 \pm 5.49$ & \\
\hline Years 13 & $194.85 \pm 13.47$ & & $51.94 \pm 4.81$ & & $65.07 \pm 5.06$ & & $43.42 \pm 4.93$ & & $34.41 \pm 3.99$ & \\
\hline Family Income & & $0.049^{\star}$ & & 0.268 & & $0.012^{\star}$ & & 0.158 & & 0.442 \\
\hline Below $\$ 5,000$ & $187.90 \pm 25.14$ & & $50.16 \pm 7.55$ & & $61.68 \pm 8.18$ & & $41.85 \pm 6.55$ & & $34.20 \pm 5.73$ & \\
\hline$\$ 5,000-10,000$ & $189.75 \pm 15.08$ & & $52.16 \pm 3.57$ & & $61.33 \pm 6.81$ & & $42.15 \pm 4.60$ & & $34.10 \pm 4.64$ & \\
\hline$\$ 10,000-20,000$ & $194.58 \pm 14.60$ & & $51.38 \pm 5.51$ & & $64.75 \pm 6.09$ & & $43.62 \pm 4.89$ & & $34.83 \pm 4.06$ & \\
\hline$\$ 30,000-40,000$ & $194.91 \pm 15.75$ & & $52.19 \pm 4.78$ & & $64.46 \pm 6.51$ & & $43.38 \pm 5.07$ & & $34.87 \pm 3.88$ & \\
\hline$\$ 40,000-50,000$ & $199.08 \pm 12.60$ & & $53.20 \pm 3.54$ & & $65.08 \pm 6.04$ & & $44.40 \pm 4.50$ & & $36.40 \pm 2.39$ & \\
\hline Above $\$ 50,000$ & $192.13 \pm 18.70$ & & $50.63 \pm 5.22$ & & $64.08 \pm 9.31$ & & $43.04 \pm 5.32$ & & $34.37 \pm 7.23$ & \\
\hline
\end{tabular}

*Non parametric tests were conducted. 
TABLE 4 | Correlations between wellness dimensions, wellness items, and overall wellness.

\begin{tabular}{|c|c|c|}
\hline & \multicolumn{2}{|c|}{ Overall wellness } \\
\hline & $r$-value & $p$-value \\
\hline \multicolumn{3}{|l|}{ Wellness dimensions } \\
\hline Physical wellness score & 0.66 & $<0.01$ \\
\hline Psychological wellness score & 0.80 & $<0.01$ \\
\hline Social wellness score & 0.71 & $<0.01$ \\
\hline Spiritual wellness score & 0.80 & $<0.01$ \\
\hline \multicolumn{3}{|l|}{ Physical wellness statements } \\
\hline My weight affects my physical development. & 0.19 & $<0.01$ \\
\hline I eat a balanced diet. & 0.29 & $<0.01$ \\
\hline Physical activity is important. & 0.29 & $<0.01$ \\
\hline Drinking Kava affects my health. & 0.37 & $<0.01$ \\
\hline Marijuana affects my health. & 0.40 & $<0.01$ \\
\hline Sniffing glue or Solvents affects my health. & 0.39 & $<0.01$ \\
\hline Using drugs such as Cocaine, Heroin ... affects my health. & 0.40 & $<0.01$ \\
\hline Drinking anything with alcohol affects my health. & 0.41 & $<0.01$ \\
\hline \multicolumn{3}{|l|}{ Psychological wellness statements } \\
\hline I can answer the question "Who am I". & 0.54 & $<0.01$ \\
\hline I always look on the bright side of things. & 0.47 & $<0.01$ \\
\hline I am able to learn from my challenges & 0.47 & $<0.01$ \\
\hline I feel competent in dealing with life challenges. & 0.47 & $<0.01$ \\
\hline I sometimes think I am a worthless individual. & 0.10 & $<0.01$ \\
\hline I don't understand what life is all about. & 0.18 & $<0.01$ \\
\hline I am uncertain about my ability to do things well in the future. & 0.02 & $<0.01$ \\
\hline I have grown up in an affectionate, accepting and loving family & 0.52 & $<0.01$ \\
\hline I believe my life has purpose right now & 0.53 & $<0.01$ \\
\hline My Family Cares for me & 0.52 & $<0.01$ \\
\hline My friends care for me & 0.48 & $<0.01$ \\
\hline I feel like I can make good decisions & 0.53 & $<0.01$ \\
\hline I like myself just the way I am & 0.47 & $<0.01$ \\
\hline \multicolumn{3}{|l|}{ Spiritual wellness statements } \\
\hline Spirituality brings me a sense of hope meaning and purpose in life. & 0.53 & $<0.01$ \\
\hline Spirituality means having a sense of connectedness to a higher power. & 0.51 & $<0.01$ \\
\hline Spirituality teaches you what is right and what is wrong & 0.58 & $<0.01$ \\
\hline Spirituality enriches a person's quality of life. & 0.55 & $<0.01$ \\
\hline Spirituality is important & 0.52 & $<0.01$ \\
\hline \multicolumn{3}{|l|}{ Social wellness statements } \\
\hline My family at home supports me. & 0.53 & $<0.01$ \\
\hline My parent/guardian is nurturing, warm and accepting. & 0.57 & $<0.01$ \\
\hline My parent/guardian takes interest in where I am, whom I am with, and what I am doing. & 0.44 & $<0.01$ \\
\hline I feel connected to my friends. & 0.40 & $<0.01$ \\
\hline I receive support from my teachers and school counselors. & 0.49 & $<0.01$ \\
\hline I feel that the people in my school care about me. & 0.52 & $<0.01$ \\
\hline I receive support from my youth group. & 0.47 & $<0.01$ \\
\hline
\end{tabular}

correlation was observed for the perceptions related to smoking marijuana $(r=0.40, p<0.01)$, using drugs $(r=0.40, p>0.01)$, and drinking alcohol $(r=0.41, p<0.01)$.

Correlations between all high self-concept variables were moderately associated with overall wellness. These included, the ability to answer the question of "who am I" and the perception of
"I always look on the bright side of things" with both scoring ( $r=$ 0.54 and $r=0.47, p<0.01)$, respectively. The belief that there is purpose to life had a moderate relationship with overall wellness $(r=0.53, p<0.01)$.

For the statements related to psychological support from family and friends, moderate relationships were also observed. 
Growing up in an affectionate and loving family $(r=0.52, p<$ $0.01)$ and being cared for by friends $(r=0.48, p<0.01)$, both had positive moderate associations with overall wellness.

In terms of spiritual wellness related statements, spirituality bringing a sense of hope $[(r=0.53, p<0.01)$ and being is connected to a higher power $(r=0.51, p<0.01)]$ are positively correlated with overall wellness. Moderate correlations were observed for both "spirituality teaches you what is right and what is wrong" $(r=0.58, p<0.01)$ "spirituality enriches a person's quality of life" $(r=0.55, p<0.01)$ and the belief that "spirituality is important" $(r=0.52, p<0.01)$.

All of the statements pertaining to social wellness have significant moderate correlations with overall wellness. Students belief in, being supported from home, had a correlation coefficient of $r=0.53$ ( $p<0.01)$. Similar results were found for the item "My parent/guardian is nurturing, warm and accepting" $(r=0.57, p<0.01)$. For items related to support from peers and school, all had moderate correlations.

\section{DISCUSSION}

The study findings indicated that the majority of the adolescents scored on the high or very high end of the wellness score scale. This was similar to a study done by Preskitt which looked at adolescent wellness amongst those aged 12-17 years. Scores computed from the survey observed that nearly $30 \%$ of students scored low levels of wellness and another, $26 \%$ scored high levels of wellness score, the majority, $48.3 \%$ scored very high scores (3).

Different levels of wellness exist may be attributed to various school programs such as physical education classes, extracurricular activities, schools visit by organizations' providing advocacy on health, support from family, from peers and teachers who take up the role of school counselors by default $(27,28)$. These activities boost adolescent wellness. A third of the participants had low scores. These could be attributed to the negative influence of factors such as lack of support, social and education expectations, and extensive use of social media. Similar results were found by Berk, the study attributed low level of wellness scores to social and academic expectations placed on adolescents (29).

The study found seven significant differences between wellness variables and the independent variables. Four significant differences were observed for ethnicity. Three of these findings saw Fijians of Itaukei decent students with higher scores when compared to those from other ethnic backgrounds for overall wellness, social and spiritual wellness. Petersen et al. in their study stated that the differences observed between ethnic groups could be potentially explained by socio cultural differences (30). This included Itaukei ethnic group having a collectivist ethos that is characterized by interdependence where communal needs take priority over individual needs. Such practice enhances social ties in the Itaukei communities creating a bond between relatives despite the distant relations; these are observed to be social networks of support that often extends a helping hand in hard times (31). In addition to social wellness, participants of Itaukei ethnic groups had higher scores for physical wellness and spiritual wellness as well. This was in contrast to the previously mentioned study conducted by Petersen et al., the study found students of Itaukei ethnicity had a low level of physical, emotional, social, and school functioning and wellbeing (30). The authors had attributed their findings to ethnic differences.

As results indicated, religion is considered sacred and important to Itaukei people. Literature also indicates this, stating that Christianity is considered core aspect of identity (32). This may potentially explain results of Itaukei participants having higher scores for spiritual wellness.

Another significant difference was observed for psychological wellness dimension and ethnicity where, Fijians of Indian descent had higher levels of psychological wellness when compared to other ethnic groups. Previous studies have found differences in ethnic background influenced psychological wellness (33, 34). These studies suggested that although it is essential to consider socio economic factors as confounders, ethnic identity has significant associations with mental health. Willard and McNamara had observed this significant association through their study and concluded that Fijians of Indian descent tend to focus more on internal mental states than Itaukei Fijians (32). This may potentially explain the significant difference of psychological wellness between the two ethnic groups.

The fifth significant difference was observed between psychological wellness and education level. Participants enrolled in the higher-class levels had higher scores when compared to those who were younger and enrolled into the lower classes. This was observed for all wellness dimensions and could be attributed to older adolescents being able to make sense of their development when compared to younger ones (35).

Two significant findings were associated with family income; overall wellness and psychological wellness. Participants with a family income of $\$ 40,000-50,000$ had higher overall wellness and psychological scores when compared with those in other income categories. Literature indicated that low income is associated with lower wellbeing, lower life satisfaction and lower quality of life $(36,37)$. Income inequality still remains an issue for Fiji and is stated to be higher in the urban areas when compared to the rural areas (38).

Results of correlation analysis found strong or very strong correlations for all dimensions. These results show that there are strong positive relationships between the perceptions of each wellness dimensions and overall wellness. The results of the study suggested that an increased sense of wellness was strongly associated with higher dimensional scores.

For the physical dimension findings, results found that perceptions of weight, diet, and physical activity as important were significantly correlated with wellness. There were also significant moderate correlations between substance use and wellness; these suggested students may recognize the potential influence of weight, diet, and physical activity on health. This is essential to address the health issues associated with these risk factors amongst the adolescent population. Past studies done in Fiji show concerns of poor dietary patterns and the use of substances amongst adolescents $(10,39,40)$.

Consistent with literature, significant correlations were also observed for psychological wellness dimensions. This study 
found significant relationships exist between positive selfconcept, self-esteem related statements and wellness. Previous studies have shown that those with high self-esteem and self-concept tend to have better mental health, academic achievements and are less likely to do drugs (16, 41-43). There is evidence of the influence of self-concept and self-esteem and further tools are to be developed to evaluate the concepts further in Fiji.

This study found that receiving support from family and friends led to better psychological wellbeing. Other studies have found similar significant findings $(13,44,45)$. These results suggest to stakeholders working with adolescent wellness, that family and friends are important influences of adolescent wellness and these relationships are to be considered. Significant findings were also observed for social wellness. The study found that family support, having a warm and nurturing parents or guardians are significantly correlated with higher sense of wellness. This is supported by other research (17). These findings suggest that adolescents view family and peers to influence their social wellness and adolescent programmes are to consider this.

Significant findings were also observed for spiritual wellness. The perception of spiritual wellness as important was moderately associated with spiritual wellness. This highlights a high sense of spiritual wellness as being important. Similar results were found for statements relating to the meaning of spiritual wellness. These findings may suggest what other studies have found. This include, having a higher sense of spiritual wellness leads to the practice of less risky behaviors such as consumption of drugs and alcohol $(46,47)$. This may be influenced by rules set as acceptable behavior in the spiritual or religious disciplines, which may strongly discourage use substance use, and deviant behavior (48). Other literature have also observed that higher sense of spiritual wellness was associated to coping mechanisms (46).

\section{LIMITATIONS}

Findings of this research must be interpreted within the context of its limitation. Due to the setting and the nature of the study participants, timing of data collection was limited. Quantitative data tool used was a self-administered questionnaire that could possibly explain the high scores of wellness observed for the study. Due the study being cross sectional, the study is limited to high school students and findings may not be generalized to all adolescent population in Fiji. Study findings included only students and teachers, it would be ideal for future research to consider parents and guardians' perception as they are vital toward achieving adolescent wellness.

\section{REFERENCES}

1. WHO. Adolescents: Health Risks and Solutions. (2018). Available online at: https://www.who.int/en/news-room/fact-sheets/detail/adolescentshealth-risks-and-solutions

\section{SUMMARY AND CONCLUSION}

The findings of this study are related to ethnicity, family income, physical activity, diet and body weight, support from peers, friends, and family, high self-concept and self-esteem, and spiritual wellness meanings. It is recommended that health education and awareness be carried out in terms of physical activity, diet, and body weight. It is also recommendedthat MoEHA research on best ways to increase parental engagement in schools. Apart from family, peer support can be a coping mechanism for adolescent and adolescent wellness programs are to consider peer support interventions. MoHMS and MoEHA have collaborated over the years to improve and encourage efforts in the school health programs. This collaboration is to continue, strengthened, and improved to allow MoHMS programs to be efficiently and effectively implemented in school settings. This collaboration is to ensure that wellness is reflected in the school health programs. Finally, there is more research effort needed to inform the wellness movement in Fiji. This study has added to the adolescent wellness pool of knowledge, however; research gaps remain. Further studies are needed to understand the broad concept of wellness and its several dimensions. The knowledge level, the perceptions, and practice of wellness amongst other population groups remain unanswered.

\section{DATA AVAILABILITY STATEMENT}

The raw data supporting the conclusions of this article will be made available by the authors, without undue reservation.

\section{ETHICS STATEMENT}

The studies involving human participants were reviewed and approved by Fiji National University's (FNU) College Health Research Ethics Committee (CHREC). The patients/participants provided their written informed consent to participate in this study.

\section{AUTHOR CONTRIBUTIONS}

LO led the writing of the article and contributed to the data analysis and interpretation of the results. MM contributed to the technical aspects of the research and data analysis. SK led the data analysis process. All authors contributed to the article and approved the submitted version.

\section{ACKNOWLEDGMENTS}

The authors thank all the participants, teachers, and schools for their enthusiastic participation in this study.

2. Pinhas-Hamiel $\mathrm{O}$, Zeitler P. The global spread of type 2 diabetes mellitus in children and adolescents. J Pediat. (2005) 146:693-700. doi: 10.1016/j.jpeds.2004.12.042

3. Preskitt J. Wellness among US adolescents ages 12-17 years. Child Care Health Dev. (2015) 41:1207-15. doi: 10.1111/cch.12248 
4. Kirsten TG, Van der Walt HJL, Viljoen CT. Health, well-being and wellness: an anthropological eco-systemic approach. Health SA Gesondheid. (2009) 14:1-7. doi: 10.4102/hsag.v14i1.407

5. Miller G, Foster LT. Critical Synthesis of Wellness Literature. Health Promotion. (2010). p. 1-32. Available online at: https://dspace.library.uvic.ca:8443/ handle/1828/2894

6. Ministry of Health and Medical Services. Fiji National Wellness Policy, 2015. (2015). Available online at: https://www.health.gov.fj/wp-content/uploads/ 2018/03/National-Wellness-Policy-for-Fiji.pdf

7. Goss HB. Wellness education : an integrated theoretical framework for fostering transformative learning (Doctoral dissertation). Queensland University of Technology, Brisbane, QLD, Australia (2011).

8. Janssen I, LeBlanc AG. Systematic review of the health benefits of physical activity and fitness in school-aged children and youth. Int J Behav Nutr Phys Act. (2010) 7:40. doi: 10.1186/1479-5868-7-40

9. Lassi ZS, Moin A, Das JK, Salam RA, Bhutta ZA. Systematic review on evidence-based adolescent nutrition interventions. Ann N Y Acad Sci. (2017) 1:34-50. doi: 10.1111/nyas.13335

10. Wate JT, Snowdon W, Millar L, Nichols M, Mavoa H, Goundar R, et al. Adolescent dietary patterns in Fiji and their relationships with standardized body mass index. Int J Behav Nutr Phys Act. (2013) 10:45. doi: 10.1186/1479-5868-10-45

11. Tremain D, Freund M, Wolfenden L, Wye P, Bowman J, Dunlop A, et al. Modifiable health risk behaviours and attitudes towards behaviour change of clients attending community-based substance use treatment services. Drug Alcohol Rev. (2017) 36:369-77. doi: 10.1111/dar.12439

12. Schulte MT, Hser YI. Substance use and associated health conditions throughout the lifespan. Public Health Rev. (2014) 35, 1-23. doi: 10.1007/BF03391702

13. Ebru IF, Cakarb FS. Perceived social support and self-esteem in adolescence. Procedia - Soc Behav Sci. (2010) 5:2338-42. doi: 10.1016/j.sbspro.2010.07.460

14. González M, Casas F, Coenders GA. Complexity approach to psychological well-being in adolescence: major strengths and methodological issues. Soc Indic Res. (2007) 80:267-95. doi: 10.1007/s11205-005-5073-y

15. Keyes CL. Mental health in adolescence: is America's youth flourishing? Am J Orthopsychiatry. (2006) 6:395-402. doi: 10.1037/0002-9432.76.3.395

16. Dudovitz RN, Chung P J, Wong MD. Teachers and coaches in adolescent social networks are associated with healthier self-concept and decreased substance use. J School Health. (2017) 87:12-20. doi: 10.1111/josh.12462

17. Bean RA, Bush KR, McKenry PC, Wilson SM. The impact of parental support, behavioral control, and psychological control on the academic achievement and self-esteem of African American and European American adolescents. $J$ Adolesc Res. (2003) 18:523-41. doi: 10.1177/0743558403255070

18. Amati V, Meggiolaro S, Rivellini G, Zaccarin S. Social relations and life satisfaction: the role of friends. Genus. (2018) 74:7. doi: 10.1186/s41118-018-0032-z

19. Puschner B, Repper J, Mahlke C, Nixdorf R, Basangwa D, Nakku J, et al. Using peer support in developing empowering mental health services (upsides): background, rationale and methodology. Ann Glob Health. (2019) 85:53. doi: 10.5334/aogh.2435

20. Michaelson V, King, N, Inchley J, Currie D, Brooks F, Pickett W. Domains of spirituality and their associations with positive mental health: a study of adolescents in Canada, England and Scotland. Prevt Med. (2019) 125:12-8. doi: 10.1016/j.ypmed.2019. 04.018

21. Ministry of Health and Medical Services. Fiji Adolescent Health Situational Analysis: 2016. (2016). Retrieved from: https://www.aidsdatahub.org/sites/ default/files/Fiji_Adolescent_Health_Situational_Analysis_2016.pdf

22. Fiji Bureau of Statistics. 2017 Population and Housing Census. (2018). Available online at: http://kostat.go.kr/portal/eng/pressReleases/8/7/index. board? bmode $=$ download $\&$ bSeq $=\& a S e q=370993 \&$ ord $=2$

23. Spur S. Student perceptions of adolescent wellness. (Degree of Doctor of Philosophy) University of Saskatchewan, Saskatoon, SK, Canada (2009).

24. Goodwin IC. The relationship between perceived wellness and stages of change for exercise among rural African American women. (Dissertation) Georgia State University, Atlanda, GA, USA (2009).

25. Adams T, Bezner J, Steinhardt M. The conceptualization and measurement of perceived wellness: integrating balance across and within dimensions.
Am J Health Promot. (1997) 11:208-18. doi: 10.4278/0890-1171-11. 3.208

26. Lakshmi S, Mohideen. A. Issue in reliability and validity of research. Int J Manag Res Rev. (2013) 3:2752-6. Retrieved from: www.ijmrr.com

27. Brewer HJ, Nichols R, Leight JM, Clark GE. Preparing physical and health education teacher candidates to create a culture of wellness in schools: new curriculum, new message. J Phys Educ Recreation Dance. (2017) 88:1420. doi: 10.1080/07303084.2017.1367743

28. Pufall JE, Hatfield D, Connolly N. Every school healthy: creating local impact through national efforts. J Sch Health. (2020) 90:9951003. doi: 10.1111/josh.12963

29. Berk LE. Cognitive development in adolescence. In: Mosher J, editor. Infants, Children, and Adolescents. 7th ed. Boston, MA: Ally-Bacon (2012). pp. 564-97.

30. Petersen S, Mavoa H, Swinburn B, Waqa G, Goundar R, Moodie M. Healthrelated quality of life is low in secondary school children in Fiji. Int J Pediatr. (2012) 2012:294530. doi: 10.1155/2012/294530

31. Grambeau ML. Causes and Perceptions: An Exploratory Study of Suicide in Indo-Fijian \& Fijian Youth Independent Study Project (ISP) Collection. (2007). Retrieved from http://digitalcollections.sit.edu/isp_collection/218

32. Willard AK, McNamara RA. The minds of $\operatorname{god}(\mathrm{s})$ and humans: differences in mind perception in Fiji and North America. Cogn Sci. (2019) 43:e12703. doi: $10.1111 / \operatorname{cogs} .12703$

33. Chang TE, Weiss AP, Marques L, Baer L, Vogeli C, Trinh HT et al. Race/ethnicity and other social determinants of psychological well-being and functioning in mental health clinics. $J$ Health Care Poor Underserved. (2014) 25:1418-31. doi: 10.1353/hpu.2014. 0138

34. Molix L, Bettencourt BA. Predicting well-being among ethnic minorities: psychological empowerment and group identity. J Appl Soc Psychol. (2010) 40:513-33. doi: 10.1111/j.1559-1816.2010.00585.x

35. Hockenberry MJ, Wilson, D. Nursing Care of Infants and Children. Elsevier St. Louis, MO: Mosby (2007).

36. Campara JP, Vieira KM, Potrich, ACG. Overall life satisfaction and financial well-being: revealing the perceptions of the beneficiaries of the Bolsa Família Program. "Revista De Administração Pública. (2017) 51:182-200. doi: 10.1590/0034-7612156168

37. Gildner TE, Liebert MA, Capistrant BD, D’Este C, Snodgrass JJ, Kowal P. Perceived income adequacy and well-being among older adults in six lowand middle-income countries. J Gerontol B Psychol Sci Soc Sci. (2019) 74:51625. doi: 10.1093/geronb/gbw145

38. Gounder R, Xing, Z. The measurement of inequality in Fiji's household income distribution: some empirical results. Int J Soc Eco. (2012) 39:26480. doi: 10.1108/03068291211205695

39. Puamau ES, Roberts G, Schmich L, Power R. Drug and alcohol use in Fiji: a review. Pacific Health Dialog. (2011) 17:165-71.

40. WHO. Global School-Based Student Health Survey. (2016). Available online at: https://www.who.int/ncds/surveillance/gshs/gshs_fs_fiji_2016.pdf

41. Li HC, Chan SL, Chung OK, Chui ML. Relationships among mental health, self-esteem and physical health in Chinese adolescents: an exploratory study. J Health Psychol. (2010) 15:96-106. doi: 10.1177/1359105309 342601

42. Myers DG. Social Psychology. New York, NY: McGraw-Hill International Edition (2010).

43. MacPhee AR, Andrews JJ. Risk factors for depression in early adolescence. Adolescence. (2006) 41:435-66.

44. Ahmad Zamani Z, Nasir R, Khairudin R, Wan Sulaiman WS. Family functioning as predictor towards self-concept among delinquent adolescents. Pertanika J Soc Sci Humanit. (2011). 19:83-9.

45. Kumari L. Influencing factors of mental health of adolescents at school level influencing factors of mental health of adolescents at school level. J Humanit Soc Sci. (2012) 5:48-56. doi: 10.9790/0837-0544856

46. Cotton S, Zebracki K, Rosenthal SL, Tsevat J, Drotar D. Religion/spirituality and adolescent health outcomes: a review. J Adolesc Health. (2006) 38:47280. doi: 10.1016/j.jadohealth.2005.10.005

47. Yonker JE, Schnabelrauch CA, Dehaan LG. The relationship between spirituality and religiosity on psychological outcomes in adolescents and emerging adults: a meta-analytic review. J Adolesc. (2012) 35:299314. doi: 10.1016/j.adolescence.2011.08.010 
48. Regnerus MD. Religion and positive adolescent outcomes: a review of research and theory. Rev Relig Res. (2003) 44:394-413. doi: 10.2307/ 3512217

Conflict of Interest: The authors declare that the research was conducted in the absence of any commercial or financial relationships that could be construed as a potential conflict of interest.
Copyright $\odot 2021$ Odrovakavula, Mohammadnezhad and Khan. This is an openaccess article distributed under the terms of the Creative Commons Attribution License (CC BY). The use, distribution or reproduction in other forums is permitted, provided the original author $(s)$ and the copyright owner(s) are credited and that the original publication in this journal is cited, in accordance with accepted academic practice. No use, distribution or reproduction is permitted which does not comply with these terms. 